\title{
PERENCANAAN PERAWATAN MESIN UNTUK MENURUNKAN BIAYA PERAWATAN DENGAN MENGGUNAKAN METODE MARKOV CHAIN
}

\author{
Wahyu Eni', Henry Susiawan ${ }^{2}$
}

\begin{abstract}
For this time, machine and tools are much wear in some factory to support human in produce something. And so machine and tools it self are an object which be able to damaged, then be needed to take care of those thing in a continue manner. In a logic manner could be arithmeticed that with continued machine treatment will more decrease the cost of factory every periode than the consequence cost of machine damage. Especially in order to get a good productivity, good quality and low cost level, so one of method to prevent this thing is using Markov Chain method. Base on result analyst, then known that the treatment of Root Washer machine are Korective Treatment Planning on weight status and Prohibition treatment on light in weight and average status. Then the treatment cost motion on Root Whasher machine have a cost judgment result Rp. 492.977,-
\end{abstract}

\section{Key Words : Treatment, Cost, Markov Chain Method.}

\section{PENDAHULUAN}

Kemajuan teknologi era sekarang ini mengakibatkan kebutuhan akan tenaga manusia mulai digeser untuk digantikan dengan mesin atau peralatan produksi lainnya. Mesin dan peralatan yang dalam kondisi baik akan dapat melancarkan jalannya proses produksi. Untuk menjaga agar mesin-mesin tersebut dapat digunakan dengan sebaik mungkin maka dibutuhkan kegiatan perawatan atau maintanance yang kontinyu.

Dalam suatu perusahaan masalah perawatan atau maintanance seringkali diabaikan, sehingga terjadilah kegiatan perawatan yang tidak teratur. Kegiatan perawatan ini baru dilakukan setelah kondisi mesin-mesin tersebut rusak berat dan tidak dapat dioperasikan lagi. Jika hal tersebut terjadi maka akan sangat merugikan perusahaan karena biaya yang ditimbulkan relatif besar, seperti biaya perbaikan dan biaya down time akibat mesin tersebut tidak berproduksi. Kerugian lain adalah proses produksi tidak berjalan lancar dan kualitas output yang dihasilkan rendah serta akan berpengaruh terhadap turunnya kepercayaan konsumen pada perusahaan akibat produksi yang tidak stabil.

Demikan pula yang dilakukan oleh PT. SARI TANAM PRATAMA PONOROGO, perusahaan ini melakukan perawatan terhadap mesin-mesin yang ada secara tidak teratur. Perawatan yang dilakukan oleh perusahaan biasanya menunggu sampai mesin mengalami kerusakan berat dan mesin tersebut tidak dapat dioperasikan lagi. Dari keadaan tersebut maka menyebabkan biaya down 
time relatif tinggi, hal ini dikarenakan mesin-mesin yanga ada harus dilakukan perbaikan.

Dengan mengadakan kegiatan perawatan mesin yang kontinyu meliputi pengecekan, perbaikan atas kerusakan yang ada serta penyesuaian atau penggantian spare parts menjadikan kontinuitas produksi dapat terjamin. Perencanaan perawatan ditujukan untuk meningkatkan efisiensi dengan mengurangi kemacetan sekecil-kecilnya.

\section{TINJAUAN PUSTAKA}

Tujuan utama dari fungsi perawatan ini adalah :

1. Kemampuan berproduksi dapat memenuhi kebutuhan sesuai dengan rencana produksi.

2. Menjaga kualitas dan tingkat yang tepat untuk memenuhi apa yang dibutuhkan oleh produk itu sendiri dan kegiatan produksi yang tidak terganggu.

3. Untuk membantu mengurangi pemakaian dan penyimpangan yang di luar batas dan menjaga modal yang diinvestasikan dalam perusahaan selama waktu yang ditentukan sesuai dengan kebijaksanaan perusahaan mengenai investasi tersebut.

4. Untuk mencapai tingkat biaya perawatan serendah mungkin, dengan melaksanakan kegiatan perawatan secara efektif dan efisien keseluruhnya.

5. Agar keselamatan pekerja lebih terjamin.
6. Mengadakan suatu kerja sama yang erat dengan fungsi-fungsi utama lainnya dari suatu perusahaan, dalam rangka untuk mencapai tujuan utama perusahaan yaitu tingkat keuntungan atau return of investment yang sebaik mungkin dan total biaya yang rendah. (Soffyan Assauri, 1978, hal 88)

\section{Proses Markov Chain}

Sebelum kita membahas metode untuk menentukan kemungkinan transisi akan diuraikan dahulu tentang pengertian dasar proses stokastik, karena metode Markov Chain merupakan kejadian khusus dari proses stokastik (Tjuju T. Dimyati dan Ahmad Dimyati, 1992, hal 320).

Proses stokastik $\left\{X_{(t)}: t \varepsilon T\right\}$ adalah sekelompok variabel random $X_{(t)}$ dimana $t$ diambil dari sekumpulan data (T) yang telah diketahui. Seringkali $T$ merupakan suatu kelompok bilangan bulat non negatif dan $\mathrm{X}_{(\mathrm{t})}$ menyatakan karakteristik yang dapat diukur dari sesuatu pada waktu t. karena $\mathrm{X}_{(\mathrm{t})}$ adalah variabel random maka tidak dapat diketahui dengan pasti pada status manakah suatu proses akan berada pada waktu $t$, bila $t$ menunjukkan saat terjadinya status di waktu yang akan datang. Dimana $\mathrm{t}=0,1,2, \ldots$

(P. Siagion, 1987, hal 490).

Suatu proses stokastik dikatakan memiliki sifat markovian jika memenuhi syarat sebagai berikut :

$P\left\{X_{t+1}=j \mid X_{0}=k_{0}, X_{1}=k_{1}, ., X_{t-1}, X_{t}=i\right\}$ $=P\left\{X_{t+1}=j \mid X_{t}=i\right\}$, dimana $\mathrm{t}=0,1,2, \ldots$

(Frederick S. Hiller and Gerald J.

Lieberman, 1981, hal 372). 
Probabilitas bersyarat $P\left\{X_{t+1}=j \mid X_{t}=i\right\}$ disebut sebagai probabilitas transisi.

Jika untuk masing-masing i dan $\mathrm{j}, P\left\{X_{t+1}=\mathrm{j}\right.$ $\left.\mid X_{\mathrm{t}}=\mathrm{i}\right\}=\mathrm{P}\left\{\mathrm{X}_{\mathrm{t}}=\mathrm{j} \mid \mathrm{X}_{0}=\mathrm{i}\right\}$, untuk $\mathrm{t}=$ $0,1,2, \ldots$ maka disebut probabilitas transisi (satu langkah) dan biasanya dilambangkan oleh $P_{i j}$. Sedangkan $P\left\{X_{t+n}=j \mid X_{t} i\right\}=P$ $\left\{X_{n}=j \quad \mid X_{0}=i\right\}$, dimana $n=0,1,2, \ldots$, untuk $\mathrm{t}=0,1,2, \ldots$ Probabilitas bersyarat ini biasanya dilambangkan dengan $P_{i j}^{(n)}$ dan disebut sebagai probabilitas transisi $n$ langkah. Jadi $\mathrm{P}_{\mathrm{ij}}{ }^{(\mathrm{n})}$ adalah probabilitas bersyarat bahwa variabel random $X_{(t)}$, yang dimulai dari status i, akan berada pada status $\mathrm{j}$ setelah $\mathrm{n}$ langkah.

Untuk $\mathrm{n}=0, \mathrm{P}_{\mathrm{ij}}^{(\mathrm{n})}$ maka $\mathrm{P}\left\{\mathrm{X}_{\mathrm{o}}=\mathrm{j} \mid \mathrm{X}_{\mathrm{o}}=\mathrm{i}\right\}$ sehingga mengakibatkan bernilai 1 ketika $\mathrm{i}=$ $\mathrm{j}$ dan 0 ketika $\mathrm{i}=\mathrm{j}$.

Dimana $\mathrm{P}_{\mathrm{ij}}^{(\mathrm{n})}$ harus memenuhi syarat sebagai berikut:

$P_{i j}^{(n)} 0$, untuk semua $i$ dan $j$, dan $n=0,1,2 \ldots$. ${ }^{\mathrm{M}} \Sigma_{\mathrm{j}=0} \quad \mathrm{P}_{\mathrm{ij}}^{(\mathrm{n})}=\mathrm{i}$, untuk semua $\mathrm{i}$ dan $\mathrm{n}=$ $0,1,2 \ldots$

Probabilitas transisi dinyatakan dalam bentuk matriks adalah sebagai berikut :

$P^{(n)}=$\begin{tabular}{|c|ccc|}
\hline Status & 0 & 1 & 2 \\
\hline 0 & $P_{00}{ }^{(n)}$ & $\ldots \ldots \ldots \ldots$ & $P_{0 M}{ }^{(n)}$ \\
1 & $\vdots$ & $\vdots$ & $\vdots$ \\
$M$ & $P_{M 0}{ }^{(n)}$ & $\ldots \ldots \ldots \ldots$ & $P_{M M}{ }^{(n)}$ \\
\hline
\end{tabular}

Untuk $\mathrm{n}=0,1,2, \ldots \ldots$.

atau

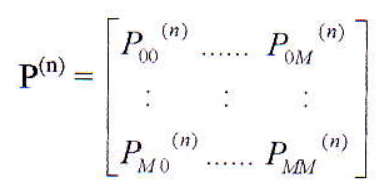

Sifat Markov Chain dalam jangka panjang, probabilitasnya menjadi status mapan (steady state). Untuk Markov Chain ergodic ( positif dan terjadi berulang-ulang) dan tak dapat diperkecil lagi maka :

limit $P_{i j}^{(n)}$ nyata ada dan tidak tergantung pada i.

$n \rightarrow \infty$

Selain daripada itu limit $P_{i j}^{(n)}=\pi_{\mathrm{j}}$,

Dimana $\pi_{\mathrm{j}}$ merupakan probabilitas status $\mathrm{j}$ yang memenuhi persyaratan steady state.

$\pi_{\mathrm{j}}>0$

$\pi \mathrm{j}=\sum_{i=0}^{M} \pi_{j} P_{i j}$ untuk $\mathrm{j}=0,1,2 \ldots . \mathrm{M}$

$$
\sum_{j=0}^{M} \pi j=1
$$

(Richard Bronson, 1988, hal 260)

Markov Chain Data yang diperlukan adalah:

* Data Transisi status

* Data waktu

* Data biaya

* Tak perlu menggunakan pemecahan statistik

* Perencanaan selang perawatan mesin

\section{Penaksiran Parameter Markov}

Proses Markov berwaktu diskrit dan berstatus diskrit terbatas $X_{(t)}, t=$ $0,1,2,3, \ldots \ldots \mathrm{N}$ ditentukan hukum probabilitas secara lengkap oleh parameter $P_{i j}(i, j=1,2,3, \ldots \ldots N)$ yang disebut sebagai probabilitas transisi homogen satu langkah. Sebagai persoalan utama yang dihadapi apabila menggunakan proses Markov sebagai suatu model sistem adalah menentukan taksiran parameter-parameter tersebut dari data yang diperoleh dari sejumlah pengamatan 
Bila suatu proses Markov dengan variasi status-i, $(i=1,2,3, \ldots \ldots . N)$ dilakukan pengamatan pada saat-saat diskrit $\mathrm{t}(\mathrm{t}=$ $0,1,2,3$, $\mathrm{t}), \mathrm{P}_{\mathrm{ij}}(\mathrm{t})$ adalah probabilitas bersyarat suatu individu sampel berada pada status i pada saat $t$ dan berada pada status $j$ pada saat $(\mathrm{t}+1)$, maka dianggap terhadap $\mathrm{m}_{\mathrm{i}}(0)$ individu sampel berada pada status $\mathrm{k}_{0}$ pada saat nol.

\section{Untuk menaksir probabilitas}

transisi homogen satu langkah dengan cara melakukan pengamatan terhadap transisi status individu-individu yang ditarik dari $\mathrm{N}$ sampel pengamatan yang dirancang dengan metode sebagai berikut :

\section{Tabel 1}

Tabel Rancangan Pengamatan

\begin{tabular}{|c|c|c|c|c|c|}
\hline Status & $\mathbf{1}$ & $\mathbf{2}$ & $\mathbf{3}$ & $\mathbf{4}$ & Stket-1 \\
\hline 1 & $\mathrm{~m}_{11}$ & $\mathrm{~m}_{12}$ & $\mathrm{~m}_{13}$ & $\mathrm{~m}_{14}$ & $\mathrm{~m}_{1}{ }^{*}$ \\
\hline 2 & $\mathrm{~m}_{21}$ & $\mathrm{~m}_{22}$ & $\mathrm{~m}_{23}$ & $\mathrm{~m}_{24}$ & $\mathrm{~m}_{2}{ }^{*}$ \\
\hline 3 & $\mathrm{~m}_{31}$ & $\mathrm{M}_{32}$ & $\mathrm{~m}_{33}$ & $\mathrm{~m}_{34}$ & $\mathrm{~m}_{3}{ }^{*}$ \\
\hline 4 & $\mathrm{~m}_{41}$ & $\mathrm{M}_{42}$ & $\mathrm{~m}_{43}$ & $\mathrm{~m}_{44}$ & $\mathrm{~m}_{4}{ }^{*}$ \\
\hline $\begin{array}{c}\text { Jumlah } \mathrm{S} \\
\text { Priode } \\
\text { ke-t }\end{array}$ & $\mathrm{m}_{1}$ & $\mathrm{M}_{2}$ & $\mathrm{~m}_{3}$ & $\mathrm{~m}_{4}$ & \\
\hline
\end{tabular}

Dari tabel tersebut probabilitas dapat diketahui dengan :

$$
\mathrm{P}_{\mathrm{ij}}=\frac{m_{i j}}{m_{i}}
$$

Di mana :

$P_{\mathrm{ij}}=$ Probabilitas

$\mathrm{m}_{\mathrm{ij}}=$ Keadaan sistem pada status $-\mathrm{j}$

$\mathrm{m}_{\mathrm{i}}=$ Jumlah sistem pada status $-\mathrm{j}$

\section{Biaya Down Time}

Akibat dari sistem tidak produktif yang diakibatkan sistem dalam perawatan atau perbaikan mengakibatkan hilangnya profit karena sistem tidak berproduksi. Biaya tersebut disebut biaya down time. Elemen-elemen biaya yang menentukan biaya down time adalah biaya operator mesin, hilangnya sebagian output produksi atau umumnya dinyatakan dalam profit persatuan waktu yang hilang.

\section{Biaya Penyelenggaraan Perawatan Pencegahan}

Jadi biaya perawatan pencegahan item-i dilambangkan dengan $\mathrm{C}_{1 \mathrm{i}}$ maka dapat dinyatakan sebagai berikut :

$\mathrm{C}_{\mathrm{n}}=($ Waktu rata-rata perawatan X Biaya down time per-jam

pencegahan per-bulan ) + Biaya tetap

\section{Biaya Kerusakan}

$\mathrm{C}_{2 \mathrm{i}}=$ ( Waktu rata-rata kerusakan X Biaya down time per-jam per-bulan ) + Biaya tetap

\section{Biaya Rata-rata Ekspektasi}

$$
\mathrm{E}=\sum_{j 0}^{M} \pi_{j} C(j)
$$

(Pangestu, Marwan, Hani ; 1994 : 193)

\section{METODOLOGI PENELITIAN}

$$
\text { Adapun langkah-langkah }
$$

pengerjaan tugas akhir ini adalah sebagai berikut:

1. Perhitungan probabilitas status untuk masing-masing mesin

2. Perhitungan probabilitas status untuk masing-masing item 
3. Perencanaan Perawatan yang diusulkan Untuk mendapatkan perawatan yang optimal sehingga bisa mengurangi biaya perawatan, maka diusulkan empat perencanaan perawatan mesin yang didapat dari perubahan matrik transisi awal sesuai dengan tindakan yang dilakukan. Dari keempat usulan tersebut yang akan dipilih adalah usulan yang mempunyai biaya rata-rata ekspektasi terkecil.

4. Analisa Biaya Perawatan Sistem

Untuk menentukan model yang digunakan untuk menentukan besarnya biaya perawatan dan besarnya biaya yang hilang akibat adanya down time, maka biaya-biaya yang timbul ada dan tidaknya perencanaan perawatan adalah :
* Besarnya biaya down time ditentukan oleh pihak perusahaan.

* Biaya penyelenggaraan perawatan pencegahan adalah biaya penyelenggaraan yang ditetapkan sebagai jumlah biaya down time yang timbul akibat perawatan pencegahan.

\section{HASIL DAN PEMBAHASAN}

\section{Probabilitas Transisi Mesin Root Whasher}

Dengan mengolah data dari tabel B-1 dan C-1 pada lampiran maka dapat disusun suatu tabel probabilitas transisi seperti di bawah ini :

\section{Tabel 2}

Probabilitas Transisi Mesin Root Whasher

\begin{tabular}{|c|c|c|c|c|c|c|c|c|c|c|}
\hline \multirow{2}{*}{ Bulan } & \multicolumn{10}{|c|}{ Status } \\
\hline & $\mathbf{P}_{11}$ & $P_{12}$ & $P_{13}$ & $P_{14}$ & $P_{22}$ & $P_{23}$ & $\mathbf{P}_{24}$ & $\mathbf{P}_{33}$ & $\mathbf{P}_{34}$ & $\mathbf{P}_{41}$ \\
\hline Juni & $1 / 1$ & 0 & 0 & $1 / 1$ & - & - & - & $1 / 1$ & 0 & - \\
\hline Juli & $1 / 2$ & 0 & 0 & $1 / 2$ & - & - & - & 0 & $1 / 1$ & - \\
\hline Agustus & $1 / 1$ & 0 & 0 & 0 & 0 & 0 & $1 / 1$ & $1 / 1$ & 0 & - \\
\hline September & - & 0 & 0 & 0 & $1 / 1$ & $1 / 1$ & 0 & - & - & $1 / 1$ \\
\hline Oktober & $1 / 2$ & $1 / 2$ & $1 / 2$ & 0 & 0 & 0 & 0 & - & - & - \\
\hline Nopember & $1 / 2$ & 0 & 0 & 0 & 0 & 0 & $1 / 1$ & - & - & - \\
\hline Jumlah & 3,5 & 0,5 & 0,5 & 1,5 & 1 & 1 & 2 & 2 & 1 & 1 \\
\hline Rata-rata & 0,583 & 0,083 & 0,083 & 0,25 & 0,25 & 0,25 & 0,5 & 0,666 & 0,333 & 1 \\
\hline
\end{tabular}

Matrik transisi satu langkah mesin Root Whasher yang merupakan perawatan yang dilakukan oleh perusahaan adalah :

$\mathbf{P}_{\mathbf{0}}=$\begin{tabular}{|c|c|c|c|c|}
\hline $\mathbf{i} \mathbf{j}$ & $\mathbf{1}$ & $\mathbf{2}$ & $\mathbf{3}$ & $\mathbf{4}$ \\
\hline $\mathbf{1}$ & 0,6 & 0,1 & 0,1 & 0,2 \\
\hline 2 & 0 & 0,25 & 0,25 & 0,5 \\
\hline 3 & 0 & 0 & 0,667 & 0,333 \\
\hline 4 & 1 & 0 & 0 & 0 \\
\hline
\end{tabular}

Dengan menggunakan persamaan serta hasil matriks transisi tersebut, dalam jangka panjang probabilitas terjadinya transisi dalam keadaan steady state dapat ditulis sebagai berikut :

$$
\begin{gathered}
{\left[\begin{array}{llll}
\pi_{1} & \pi_{2} & \pi_{3} & \pi_{4}
\end{array}\right]\left[\begin{array}{rrrr}
0,6 & 0,1 & 0,1 & 0,2 \\
0 & 0,25 & 0,25 & 0,5 \\
0 & 0 & 0,5 & 0,5 \\
, & \wedge & \circ & \wedge
\end{array}\right]} \\
\quad=\left[\begin{array}{llll}
\pi_{1} & \pi_{2} & \pi_{3} & \pi_{4}
\end{array}\right]
\end{gathered}
$$




$$
\operatorname{dan} \pi_{1}+\pi_{2}+\pi_{3}+\pi_{4}=1
$$

maka akan didapat persamaan sebagai berikut :

1. $\pi_{1}+\pi_{2}+\pi_{3}+\pi_{4}=1$

2. $0,6 \pi_{1}+$

3. $0,1 \pi_{1}+0,25 \pi_{2}$

$\pi_{4}=\pi_{1}$

$=\pi_{2}$

4. $0,1 \pi_{1}+0,25 \pi_{2}+0,5 \pi_{3}=\pi_{3}$

5. $0,2 \pi_{1}+0,5 \pi_{2}+0,5 \pi_{3}=\pi_{4}$

Hasil dari persamaan tersebut didapatkan nilai :

$$
\begin{aligned}
& \pi_{1}=0,5327 \\
& \pi_{2}=0,0585 \\
& \pi_{3}=0,1816 \\
& \pi_{4}=0,2231
\end{aligned}
$$

\section{Perencanaan Perawatan Usulan Mesin}

\section{Root Whasher}

Perawatan korektif pada status 4 dan perawatan pencegahan pada status 3

Matriks transisinya adalah sebagai berikut :

$\mathbf{P}_{\mathbf{1}}=$\begin{tabular}{|c|c|c|c|c|}
\hline $\mathbf{i} \mathbf{j}$ & $\mathbf{1}$ & $\mathbf{2}$ & $\mathbf{3}$ & $\mathbf{4}$ \\
\hline 1 & 0,6 & 0,1 & 0,1 & 0,2 \\
\hline 2 & 0 & 0,25 & 0,25 & 0,5 \\
\hline 3 & 0 & 1 & 0 & 0 \\
\hline 4 & 1 & 0 & 0 & 0 \\
\hline
\end{tabular}

Dengan menggunakan persamaan serta hasil matriks transisi tersebut, dalam jangka panjang probabilitas terjadinya transisi dalam keadaan steady state dapat ditulis sebagai berikut :

$\left[\begin{array}{llll}\pi_{1} & \pi_{2} & \pi_{3} & \pi_{4}\end{array}\right]\left[\begin{array}{cccc}0,6 & 0,1 & 0,1 & 0,2 \\ 0 & 0,25 & 0,25 & 0,5 \\ 0 & 1 & 0 & 0 \\ 1 & n & n & n\end{array}\right]$

$$
=\left[\begin{array}{llll}
\pi_{1} & \pi_{2} & \pi_{3} & \pi_{4}
\end{array}\right]
$$

dan $\pi_{1}+\pi_{2}+\pi_{3}+\pi_{4}=1$ maka akan didapat persamaan sebagai berikut :

1. $\pi_{1}+\pi_{2}+\pi_{3}+\pi_{4}=1$

2. $0,6 \pi_{1}+\quad \pi_{4}=\pi_{1}$

3. $0,1 \pi_{1}+0,25 \pi_{2}+\pi_{3}=\pi_{2}$

4. $0,1 \pi_{1}+0,25 \pi_{2}=\pi_{3}$

5. $0,2 \pi_{1}+0,5 \pi_{2}=\pi_{4}$

Hasil dari persamaan tersebut didapatkan nilai :

$$
\begin{aligned}
& \pi_{1}=0,5169 \\
& \pi_{2}=0,1736 \\
& \pi_{3}=0,0877 \\
& \pi_{4}=0,2191
\end{aligned}
$$

Perawatan korektif pada status 3 dan 4 serta perawatan pencegahan pada status 2

$\mathbf{P}_{2}=$\begin{tabular}{|c|c|c|c|c|}
\hline $\mathbf{i} \mathbf{j}$ & $\mathbf{1}$ & $\mathbf{2}$ & $\mathbf{3}$ & $\mathbf{4}$ \\
\hline 1 & 0,6 & 0,1 & 0,1 & 0,2 \\
\hline 2 & 1 & 0 & 0 & 0 \\
\hline 3 & 1 & 0 & 0 & 0 \\
\hline 4 & 1 & 0 & 0 & 0 \\
\hline
\end{tabular}

Dengan menggunakan persamaan serta hasil matriks transisi tersebut, dalam jangka panjang probabilitas terjadinya transisi dalam keadaan steady state dapat ditulis sebagai berikut :

$$
\begin{gathered}
{\left[\begin{array}{llll}
\pi_{1} & \pi_{2} & \pi_{3} & \pi_{4}
\end{array}\right]\left[\begin{array}{cccc}
0,6 & 0,1 & 0,1 & 0,2 \\
1 & 0 & 0 & 0 \\
1 & 0 & 0 & 0 \\
1 & 0 & 0 & 0
\end{array}\right]} \\
\quad=\left[\begin{array}{llll}
\pi_{1} & \pi_{2} & \pi_{3} & \pi_{4}
\end{array}\right] \\
\quad \text { dan } \pi_{1}+\pi_{2}+\pi_{3}+\pi_{4}=1
\end{gathered}
$$

maka akan didapat persamaan sebagai berikut :
1. $\pi_{1}+\pi_{2}+\pi_{3}+\pi_{4}=1$
2. $0,6 \pi_{1}+\pi_{2}+\pi_{3}+\pi_{4}=\pi_{1}$
$3.0,1 \pi_{1}=\pi_{2}$ 

4. $0,1 \pi_{1}$
$=\pi_{3}$
5. $0,2 \pi_{1}$
$=\pi_{4}$

Hasil dari persamaan tersebut didapatkan nilai :

$$
\begin{aligned}
& \pi_{1}=0,7009 \\
& \pi_{2}=0,0588 \\
& \pi_{3}=0,0588 \\
& \pi_{4}=0,1773
\end{aligned}
$$

Perawatan korektif pada status 4 dan perawatan pencegahan pada status 2 dan 3

$\mathbf{P}_{3}=$\begin{tabular}{|c|c|c|c|c|}
\hline $\mathbf{i} \mathbf{j}$ & $\mathbf{1}$ & $\mathbf{2}$ & $\mathbf{3}$ & $\mathbf{4}$ \\
\hline 1 & 0,6 & 0,1 & 0,1 & 0,2 \\
\hline 2 & 1 & 0 & 0 & 0 \\
\hline 3 & 0 & 1 & 0 & 0 \\
\hline 4 & 1 & 0 & 0 & 0 \\
\hline
\end{tabular}

Dengan menggunakan persamaan serta hasil matriks transisi tersebut, dalam jangka panjang probabilitas terjadinya transisi dalam keadaan steady state dapat ditulis sebagai berikut :

$\left[\begin{array}{llll}\pi_{1} & \pi_{2} & \pi_{3} & \pi_{4}\end{array}\right]\left[\begin{array}{cccc}0,6 & 0,1 & 0,1 & 0,2 \\ 1 & 0 & 0 & 0 \\ 0 & 1 & 0 & 0 \\ 1 & 0 & 0 & 0\end{array}\right]$

$$
=\left[\begin{array}{llll}
\pi_{1} & \pi_{2} & \pi_{3} & \pi_{4}
\end{array}\right]
$$$$
\text { dan } \pi_{1}+\pi_{2}+\pi_{3}+\pi_{4}=1
$$

maka akan didapat persamaan sebagai berikut :

$$
\begin{aligned}
& \text { 1. } \pi_{1}+\pi_{2}+\pi_{3}+\pi_{4}=1 \\
& \text { 2. } 0,6 \pi_{1}+\pi_{2}+\pi_{4}=\pi_{1} \\
& \text { 3. } 0,1 \pi_{1}+\pi \quad=\pi_{2} \\
& \text { 4. } 0,1 \pi_{1}=\pi_{3} \\
& \text { 5. } 0,2 \pi_{1}=\pi_{4}
\end{aligned}
$$

Hasil dari persamaan tersebut didapatkan

\begin{tabular}{|c|c|c|c|c|c|c|c|c|c|c|}
\hline \multirow{2}{*}{ Bulan } & \multicolumn{10}{|c|}{ Status } \\
\hline & $P_{11}$ & $\mathbf{P}_{12}$ & $P_{13}$ & $P_{14}$ & $\mathbf{P}_{22}$ & $\mathbf{P}_{23}$ & $\mathbf{P}_{24}$ & $\mathbf{P}_{33}$ & $\mathbf{P}_{34}$ & $\mathbf{P}_{41}$ \\
\hline Juni & $1 / 1$ & 0 & 0 & $1 / 1$ & - & - & - & $1 / 1$ & 0 & - \\
\hline Juli & $1 / 2$ & 0 & 0 & $1 / 2$ & - & - & - & 0 & $1 / 1$ & - \\
\hline Agustus & $1 / 1$ & 0 & 0 & 0 & 0 & 0 & $1 / 1$ & $1 / 1$ & 0 & - \\
\hline September & - & 0 & 0 & 0 & $1 / 1$ & $1 / 1$ & 0 & - & - & $1 / 1$ \\
\hline Oktober & $1 / 2$ & $1 / 2$ & $1 / 2$ & 0 & 0 & 0 & 0 & - & - & - \\
\hline Nopember & $1 / 2$ & 0 & 0 & 0 & 0 & 0 & $1 / 1$ & - & - & - \\
\hline Jumlah & 3,5 & 0,5 & 0,5 & 1,5 & 1 & 1 & 2 & 2 & 1 & 1 \\
\hline Rata-rata & 0,583 & 0,083 & 0,083 & 0,25 & 0,25 & 0,25 & 0,5 & 0,666 & 0,333 & 1 \\
\hline
\end{tabular}
nilai :

$$
\begin{aligned}
& \pi_{1}=0,6643 \\
& \pi_{2}=0,1107 \\
& \pi_{3}=0,0552 \\
& \pi_{4}=0,1662
\end{aligned}
$$

\section{HASIL DAN PEMBAHASAN}

\section{Probabilitas Transisi}

Dengan maka dapat disusun suatu tabel probabilitas transisi seperti di bawah ini :

Tabel 3

Probabilitas Transisi Mesin Root Whasher 
Matrik transisi satu langkah mesin Root Whasher yang merupakan perawatan yang dilakukan oleh perusahaan adalah :

$\mathbf{P}_{0}=$\begin{tabular}{|c|c|c|c|c|}
\hline $\mathbf{i} \mathbf{j}$ & $\mathbf{1}$ & $\mathbf{2}$ & $\mathbf{3}$ & $\mathbf{4}$ \\
\hline 1 & 0,6 & 0,1 & 0,1 & 0,2 \\
\hline 2 & 0 & 0,25 & 0,25 & 0,5 \\
\hline 3 & 0 & 0 & 0,667 & 0,333 \\
\hline 4 & 1 & 0 & 0 & 0 \\
\hline
\end{tabular}

Dengan menggunakan persamaan serta hasil matriks transisi tersebut, dalam jangka panjang probabilitas terjadinya transisi dalam keadaan steady state dapat ditulis sebagai berikut :

$$
\begin{gathered}
{\left[\begin{array}{llll}
\pi_{1} & \pi_{2} & \pi_{3} & \pi_{4}
\end{array}\right]\left[\begin{array}{rrcc}
0,6 & 0,1 & 0,1 & 0,2 \\
0 & 0,25 & 0,25 & 0,5 \\
0 & 0 & 0,5 & 0,5 \\
1 & 0 & 0 & 0
\end{array}\right]} \\
\quad=\left[\begin{array}{llll}
\pi_{1} & \pi_{2} & \pi_{3} & \pi_{4}
\end{array}\right] \\
\pi_{1}+\pi_{2}+\pi_{3}+\pi_{4}=1
\end{gathered}
$$

maka akan didapat persamaan sebagai berikut :

1. $\pi_{1}+\pi_{2}+\pi_{3}+\pi_{4}=1$

2. $0,6 \pi_{1}+\quad \pi_{4}=\pi_{1}$

3. $0,1 \pi_{1}+0,25 \pi_{2}=\pi_{2}$

4. $0,1 \pi_{1}+0,25 \pi_{2}+0,5 \pi_{3}=\pi_{3}$

5. $0,2 \pi_{1}+0,5 \pi_{2}+0,5 \pi_{3}=\pi_{4}$

Hasil dari persamaan tersebut didapatkan nilai :

$$
\begin{aligned}
& \pi_{1}=0,5327 \\
& \pi_{2}=0,0585 \\
& \pi_{3}=0,1816 \\
& \pi_{4}=0,2231
\end{aligned}
$$

Probabilitas transisi pada perawatan yang dilakukan perusahaan $\left(\mathrm{P}_{0}\right)$ untuk Mesin Root Whasher, dan selanjutnya dinyatakan dalam bentuk matriks transisi sebagai berikut :

$$
P_{0}=\left[\begin{array}{cccc}
0,583 & 0,083 & 0,083 & 0,25 \\
0 & 0,25 & 0,25 & 0,5 \\
0 & 0 & 0,667 & 0,333 \\
1 & 0 & 0 & 0
\end{array}\right]
$$

Matriks Transisi Untuk Perencanaan

\section{Perawatan Yang Diusulkan}

Dari matriks transisi awal (perawatan yang dilakukan oleh perusahaan) diusulkan empat macam rencana perawatan yang selanjutnya dapat dinyatakan dalam bentuk matriks transisi $\left(\mathrm{P}_{1}, \mathrm{P}_{2}, \mathrm{P}_{3}\right.$ dan $\left.\mathrm{P}_{4}\right)$ sebagai berikut :

Perencanaan Perawatan Korektif pada status 4 dan Pencegahan pada status 3

$$
P_{1}=\left[\begin{array}{cccc}
0,583 & 0,083 & 0,083 & 0,25 \\
0 & 0,25 & 0,25 & 0,5 \\
0 & 1 & 0 & 0 \\
1 & 0 & 0 & 0
\end{array}\right]
$$

Perencanaan Perawatan Korektif pada status 3 dan 4 serta Perencanaan Perawatan pada 2

$$
P_{2}=\left[\begin{array}{cccc}
0,583 & 0,083 & 0,083 & 0,25 \\
1 & 0 & 0 & 0 \\
1 & 0 & 0 & 0 \\
1 & 0 & 0 & 0
\end{array}\right]
$$

Perencanaan Perawatan Korektif pada status 4 dan Perawatan Penegahan pada status 2 dan 3

$$
P_{3}=\left[\begin{array}{cccc}
0,583 & 0,083 & 0,083 & 0,25 \\
1 & 0 & 0 & 0 \\
0 & 1 & 0 & 0 \\
1 & 0 & 0 & 0
\end{array}\right]
$$

\section{Probabilitas Status Mesin/Item Pada Keadaan Steady State}

Dari analisa di atas, probabilitas terjadinya kerusakan ringan, kerusakan sedang, dan kerusakan berat dalam keadaan mapan (steady state) untuk jangka panjang 
untuk mesin Root Whasher adalah sebagai berikut :

\section{Tabel 4}

\section{Probabilitas Status Mesin Root Whasher}

\begin{tabular}{|c|c|c|c|c|}
\cline { 2 - 5 } \multicolumn{1}{c|}{} & \multicolumn{4}{c|}{ Probabilitas } \\
\hline & $\begin{array}{c}\text { Kerusakan } \\
\text { Ringan } \\
\pi_{2}\end{array}$ & $\begin{array}{c}\text { Kerusakan } \\
\text { Sedang } \\
\pi_{3}\end{array}$ & $\begin{array}{c}\text { Kerusakan } \\
\text { Berat } \\
\pi_{4}\end{array}$ \\
\hline $\mathrm{P}_{0}$ & 0,5327 & 0,0585 & 0,1816 & 0,2231 \\
$\mathrm{P}_{1}$ & 0,5169 & 0,1736 & 0,0877 & 0,2191 \\
$\mathrm{P}_{2}$ & 0,7009 & 0,0588 & 0,0588 & 0,1773 \\
$\mathrm{P}_{3}$ & 0,6643 & 0,1107 & 0,0552 & 0,1162 \\
$\mathrm{P}_{4}$ & 0,6525 & 0,0723 & 0,0723 & 0,1994 \\
\hline
\end{tabular}

Tabel 5

\section{Analisa Biaya}

\begin{tabular}{|l|c|c|}
\hline \multicolumn{1}{|c|}{ Keputusan } & Status & Biaya \\
\hline 1. $\begin{array}{l}\text { Tidak melakukan } \\
\text { tindakan perawatan }\end{array}$ & $1,2,3,4$ & 0 \\
2. $\begin{array}{l}\text { Perawatan } \\
\text { pencegahan } \\
\text { 3. Perawatan korektif }\end{array}$ & $1,2,3,4$ & Rp. 1.462.500,- \\
\hline
\end{tabular}

1. $\mathrm{P}_{0}$ (Perawatan Korektif Status 4 )

$$
\begin{aligned}
\mathrm{E}_{1}^{0} & =0.2231 \text { (Rp. 6.881.250,-) } \\
& =\text { Rp. 1.535.206.875,- } \\
& =\text { Rp. 1.535.207,- }
\end{aligned}
$$

2. $\mathbf{P}_{1}$ (Perawatan Korektif Status 4 dan Perawatan Pencegahan Status 3)

$$
\begin{aligned}
& \mathrm{E}_{1}{ }^{1}=0.2191 \text { (Rp. 6.881.250,-) + } \\
& \text { 0,0877 (Rp. 1.462.500,-) } \\
& =\text { Rp. 1.635.943.125,- } \\
& =\text { Rp. 1.635.943,- }
\end{aligned}
$$

3. $\mathrm{P}_{2}$ (Perawatan Korektif Status 3 dan 4 serta Perawatan Pencegahan Status 2) $\mathrm{E}_{2}^{2}=0.0588($ Rp. 6.881.250,-) + 0.1773 (Rp. 6.881.250,-) + 0.0588 (Rp.

$$
\begin{aligned}
& 1.462 .500,-) \\
& =\text { Rp. } 1.710 .658 .125,- \\
& =\text { Rp. 1. } 710.658,-
\end{aligned}
$$

4. $\mathrm{P}_{3}$ (Perawatan Korektif Status 4 serta Perawatan Pencegahan Status 2 dan 3) $\mathrm{E}_{3}{ }^{3}=0.1162($ Rp. 6.881.250,-) + 0.1107 (Rp. 1.462.500,) +0.0552 (Rp. $1.462 .500,-)$

$$
=\text { Rp. 1.042.230,- }
$$

\section{KESIMPULAN}

Berdasarkan analisa yang telah dilakukan, maka dapat diambil kesimpulan antara lain :

1. Perawatan mesin untuk Root Washer adalah Perencanaan Perawatan Korektif pada status berat, dan Perawatan Pencegahan pada status ringan dan sedang.

2. Biaya Perawatan Usulan yang terjadi mesin Root Whasher adalah Rp. 1.042.230,-

Sehingga dihasilkan penghematan biaya untuk mesin sebesar Rp. 492.977,-

\section{DAFTAR PUSTAKA}

Handi A, Taha, 1996, Riset Operasi, Jilid

2, Penerbit Binarupa Aksara, Jakarta.

Sofyan Assauri, 1980, Manajemen

Produksi, Edisi ketiga, Lembaga Penerbit Fakultas Ekonomi Universitas Indonesia, Jakarta.

Ross, Sheldon M, 1985, Introduction of Probability Models, California.

Tijms, Henk C, 1995, Stochastic Models, Amsterdam.

Tjutju, T Dimyati, Ahmad Dimyati, 1995, Operation Research Model-Model 